\title{
Firesetting among 18-23 year old un-apprehended adults: A UK community study
}

\begin{tabular}{|r|l|}
\hline Journal: & Journal of Criminological Research, Policy and Practice \\
\hline Manuscript ID & JCRPP-06-2021-0026.R1 \\
\hline Manuscript Type: & Empirical Paper \\
\hline Keywords: & $\begin{array}{l}\text { firesetter, arson, deliberate firesetting, fire lighting, youth, adolescent, } \\
\text { un-apprehended, fire interest }\end{array}$ \\
\hline \multicolumn{2}{|l}{} \\
\hline
\end{tabular}

SCHOLARONE $^{\mathrm{m}}$
Manuscripts $^{\text {Manusion }}$ 


\section{MANUSCRIPT DETAILS}

TITLE: Firesetting among 18-23 year old un-apprehended adults: A UK community study

\section{ABSTRACT:}

This study assesses the prevalence of firesetting in a sample of young UK adults age 18 to 23 years and compares their characteristics with non-firesetting individuals.

Two-hundred and forty male $(n=119,49.6 \%)$ and female $(n=121,50.4 \%)$ participants were recruited through Prolific Academic. Comparisons were made between self-reported firesetting and non-firesetting participants on a range of demographic, fire-related, and personality measures. Factors predictive of firesetting status were examined using hierarchical logistic regression.

Twenty-five percent of participants $(n=60)$ reported igniting a deliberate fire. Logistic regression was used to examine the ability of parental supervision and behavioural issues (e.g., witnessing domestic violence, experimenting with fire before age 10, and family history of firesetting), antisocial behaviours (e.g., having criminal friends, impulsivity, teenage access to fire paraphernalia, skipping class more than once per week, taken any illegal drugs, participation in criminal behaviour), and fire-related interests, attitudes, and propensities in predicting firesetting status. Factors found to distinguish firesetting and non-firesetting participants included: experimented with fire before 10 years of age, family history of firesetting, impulsivity, teenage access to fire paraphernalia, participation in criminal behaviour, and the Fire Setting Scale.

CUST_RESEARCH_LIMITATIONS/IMPLICATIONS_(LIMIT_100_WORDS) :No data available.

The results provide key information about potential risk factors relating to un-apprehended firesetting in the general population.

CUST_SOCIAL_IMPLICATIONS_(LIMIT_100_WORDS) :No data available.

This research adds to the small body of literature examining firesetting in the general population. It refines previously used methodologies, presents the first research study to examine the prevalence of firesetting behaviour in emerging adults, and enhances our understanding of un-apprehended firesetting. 
Firesetting among 18-23 year old un-apprehended adults: A UK community study 


\section{Purpose}

This study assesses the prevalence of firesetting in a sample of young UK adults age 18 to 23 years and compares their characteristics with non-firesetting individuals.

\section{Design/Methodology}

Two-hundred and forty male $(\mathrm{n}=119,49.6 \%)$ and female $(\mathrm{n}=121,50.4 \%)$ participants were recruited through Prolific Academic. Comparisons were made between self-reported firesetting and non-firesetting participants on a range of demographic, fire-related, and personality measures. Factors predictive of firesetting status were examined using hierarchical logistic regression.

\section{Findings}

\section{Twenty-five percent of participants $(n=60)$ reported igniting a deliberate fire. Logistic} regression was used to examine the ability of parental supervision and behavioural issues (e.g., witnessing domestic violence, experimenting with fire before age 10, and family history of firesetting), antisocial behaviours (e.g., having criminal friends, impulsivity, teenage access to fire paraphernalia, skipping class more than once per week, taken any illegal drugs, participation in criminal behaviour), and fire-related interests, attitudes, and propensities in predicting firesetting status. Factors found to distinguish firesetting and non-firesetting participants included: experimented with fire before 10 years of age, family history of firesetting, impulsivity, teenage access to fire paraphernalia, participation in criminal behaviour, and the Fire Setting Scale.

\section{Originality}

This research adds to the small body of literature examining firesetting in the general population. It refines previously used methodologies, presents the first research study to 
examine the prevalence of firesetting behaviour in emerging adults, and enhances our understanding of un-apprehended firesetting.

\section{Implications}

The results provide key information about potential risk factors relating to un-apprehended firesetting in the general population.

Key words: firesetter, arson, deliberate firesetting, fire lighting, youth, adolescent, unapprehended, fire interest 
The Fire and Rescue Service in England attended 65,146 deliberate fires between April 2019 and the end of March 2020 which resulted in 55 fatalities and 1,024 non-fatal injuries (Lader, 2021). However, detection rates are low with only approximately $8 \%$ of perpetrators identified and even fewer convicted of arson (Arson Control Forum, 2003). Given the significant human costs associated with intentional firesetting, practitioners, government agencies, and policy makers are rightly concerned with preventing and reducing deliberate fires. It is therefore important to understand the prevalence, nature, and correlates of firesetting in the general population, to be able to design and implement effective prevention strategies.

\section{Prevalence of un-apprehended firesetting}

Most research on firesetting has utilised apprehended samples (i.e., individuals detained in prison or secure hospitals) or individuals convicted of arson (Dickens and Sugarman, 2012). However, an emerging body of research has focused on understanding the prevalence and characteristics of un-apprehended firesetting individuals (i.e., those who have not been arrested or convicted). Blanco et al. (2010) and Vaughn et al. (2010) conducted secondary analyses of the Wave 1 National Epidemiological Survey of Alcohol and Related Condition (NESARC) survey; a nationally representative US survey. The NESARC included a single question asking participants if they had ever set a fire. Based on responses to this question, Blanco et al. (2010) and Vaughn et al. (2010) estimated that between 1 to $1.13 \%$ of adults have a lifetime history of deliberate firesetting (Blanco et al., 2010; Vaughn et al., 2010). However, this is likely to be an underestimation as respondents were questioned face to face and may therefore have been reluctant to answer the firesetting question truthfully for fear of reprisals (Dickens and Sugarman, 2012; Gannon and Barrowcliffe, 2012).

Barrowcliffe and Gannon built on the NESARC study by improving the specificity and operationalisation of the firesetting screening question and enabling anonymous 
responding. In a series of studies, Barrowcliffe and Gannon examined the prevalence and characteristics of un-apprehended firesetting individuals in the UK. Using their refined methodology, Barrowcliffe and Gannon identified that between $11 \%$ and $17.8 \%$ of UK adults self-reported having set at least one deliberate fire since the age of 10 years (Barrowcliffe and Gannon, 2015, 2016; Gannon and Barrowcliffe, 2012). These figures are notably higher than the prevalence of firesetting reported in the NESARC studies and highlights the need to further understand factors associated with firesetting in un-apprehended individuals.

Characteristics of adults who set fires

Most research has focused on identifying the psychological characteristics of apprehended adolescents and adults who set fires. Commonly reported characteristics include lack of parental supervision and involvement, and ineffectual discipline (Kolko and Kazdin, 1986; McCarty and McMahon, 2005); a history of abuse (Dickens et al., 2007; Root et al., 2008); engagement in antisocial behaviour (Kolko et al., 1985; McCarty and McMahon, 2005); an increased interest in fire, and increased levels of anger (Gannon et al., 2013; MacKay et al., 2006; Watt et al., 2015). Although there has been a focus on identifying factors associated with firesetting, there has been less interest in identifying factors that may prevent firesetting (e.g., protective factors; Gannon et al., 2012). Understanding both factors which are associated with as well as prevent firesetting are important for informing prevention and early intervention.

\section{Characteristics of un-apprehended firesetting individuals}

Little research has examined the characteristics of un-apprehended firesetting adults. The majority of research has been conducted with community samples of children and/or adolescents recruited from schools (e.g., Del Bove et al., 2008) or community firesetting intervention programmes (Del Bove and MacKay, 2011; MacKay et al., 2009; Root et al., 2008). Consequently, there is a lack of information on the characteristics of un-apprehended 
adults who set fires. To date, only two studies have examined the psychological characteristics of un-apprehended firesetting adults. Barrowcliffe and Gannon (2015) examined demographic and background factors, offence characteristics, and fire-related factors (e.g., fire interest, identification with fire, fire attitudes) in a sample of 157 community adults, recruited via a postal survey hand delivered to 5568 households, in a single district within one UK county. Firesetting adults were significantly more likely than non-firesetting adults to report having a family member with a history of firesetting, a history of self-harm, and have a father with a diagnosed mental illness. Further, firesetting adults reported significantly higher levels of fire interest, identification with fire, attitudes supportive of firesetting, and a propensity to set fires.

Barrowcliffe and Gannon (2016) extended their 2015 study by including a wider range of measures to examine in more detail the psychological characteristics of un-apprehended firesetting adults. Relative to non-firesetting adults, un-apprehended firesetting adults were significantly more likely to report a diagnosis of a behavioural problem, a mental health diagnosis, a history of suicide attempts, having been suspended from school, having experimented with fire before age 10, and having a family member who firesets. They also scored significantly higher on measures of fire interest, propensity to set fires, anger, provocation, boredom proneness and antisocial attitudes.

Whilst Barrowcliffe and Gannon's $(2015,2016)$ studies have provided important new information about un-apprehended firesetting, the majority of participants in both studies reported setting fires during adolescence only. Further, participants ages ranged from 18 to 72 years, meaning that firesetting behaviours were often being recalled over long periods of time, which may have introduced recall biases. This study therefore seeks to address limitations of previous research and examine the prevalence and characteristics of unapprehended firesetting in 18 to 23 year old UK adults. It also extends previous research by 


\title{
examining the relationship between psychological characteristics associated with
}

apprehended firesetting in an un-apprehended sample; in particular, antisocial behaviour, fire

fascination, childhood disturbances, attachment style, parental supervision, anger, and

emotional loneliness.

\begin{abstract}
Method
Participants

Participants were recruited using the crowdsourcing website, Prolific Academic.

Crowdsourcing websites enable recruitment of participants across a wide geographic area and generate samples that are more demographically diverse than university samples (Goodman and Paolacci, 2017). Filters were applied so the study was only advertised to platform users who are currently residing in the UK and age 18 to 23 years. Two hundred and seventy-six participants accessed the online questionnaire and 270 completed the study $(97.8 \%$ completion rate). Thirty participants failed at least two of the three attention checks and therefore their data was excluded. The final sample included $119(49.6 \%)$ males and 121 $(50.4 \%)$ females with a mean age of 19.98 years $(S D=1.41)$. The majority of participants identified as White British $(74.6 \%, n=179)$ and had obtained five top grade GCSEs (e.g., A* to C) $\left(89.5 \%\right.$ ), with $62.5 \%$ having three A level qualifications grades $\mathrm{A}^{*}$ to $\mathrm{C}$.
\end{abstract}

\section{Measures}

Participants completed an online battery of questionnaires comprising demographic and background factors, firesetting disclosure items, and personality measures. Internal reliability is reported in accordance with George and Mallery's (2003) criteria: $\geq .90$ excellent, $\geq .80$ good, $\geq .70$ acceptable, and $\geq .60$ questionable.

Demographic and historical background factors. This section captured demographic information including gender, ethnicity, number of siblings, psychiatric history, 
education level, and family background (e.g., parental psychiatric history, witnessing domestic violence, family finances, and family history of firesetting).

Firesetting disclosure. Participants completed three sets of questions in this section including previous firesetting behaviour, the Fire Setting Scale (FSS; Gannon and Barrowcliffe, 2012), and the Fire Proclivity Scale (FPS, Gannon and Barrowcliffe, 2012).

Previous firesetting was assessed using the self-report question developed by Gannon and Barrowcliffe (2012), which aims to assess the two most common pathways to firesetting: antisociality and fire interest. Participants were asked whether they had ever deliberately ignited a fire(s) to annoy other people, to relieve boredom, to create excitement, for insurance purposes, due to peer pressure or to get rid of evidence. Participants were requested to exclude any fires they had set before the age of 10 years, fires started accidentally, or fires started for organised events such as bonfires. Participants who endorsed this item were then requested to provide further information via a series of forced choice questions including number of deliberate fires set, age at first and last firesetting incident, if they had been formally apprehended or received therapy for their firesetting, factors precipitating the firesetting (i.e., intoxication, planning), modus operandi (i.e., use of accelerants, ignition points, distance of fire from home), motives and targets for the firesetting, and response to the firesetting (i.e., attempts to extinguish the fire).

The FSS (Gannon and Barrowcliffe, 2012) contains two subscales, each comprising 10 items, measuring Antisocial Behaviour (e.g., I like to engage in acts that are exciting and I am a rule breaker) and Fire Interest (e.g., I am attracted to fire and I get excited thinking about fire $)$. Items are rated using a 7-point Likert scale $(1=$ not at all like me, $7=$ very strongly like me). Gannon and Barrowcliffe (2012) report the FSS has good internal consistency (overall $\alpha=.86$, Antisocial Behaviour $\alpha=.80$, Fire Interest $\alpha=.85$ ). In the 
present study, internal consistency ranged from good to excellent (overall $\alpha=.90$, Antisocial Behaviour $\alpha=.81$, Fire Interest $\alpha=.94$ ).

The FPS (Gannon and Barrowcliffe, 2012) provides an indication of an individual's propensity to engage in firesetting. Participants read six hypothetical vignettes describing firesetting situations of varying degrees of severity, are asked to imagine themselves as the firesetting protagonist, and then respond to four questions using a 5-point Likert scale assessing: (1) fascination with the fire described (1 not at all fascinated to 5 very strongly fascinated), (2) behavioural propensity to act similarly (1 would definitely not have done the same to 5 would definitely have done the same), (3) general arousal to the fire described (1 would not enjoy [watching it] at all to 5 would greatly enjoy [watching] it), and (4) general antisocialism (1 would not enjoy [watching others' reaction] at all to 5 would greatly enjoy [watching others' reaction]). Gannon and Barrowcliffe (2012) report that the FPS and its subscales has questionable to good internal consistency (overall $=\alpha=.82$, fire fascination $\alpha=$ .82 , behavioural propensity $\alpha=.68$, fire arousal $\alpha=.83$, and general antisocialism $\alpha=.78$ ). In this study, internal consistency was excellent overall $(\alpha=.90)$, the fire fascination, fire arousal, and general antisocialism subscales were acceptable $(\alpha=78, \alpha=.75, \alpha=.74$ respectively), and the behavioural propensity subscale alpha was questionable $(\alpha=.62)$.

Personality measures. Personality factors identified in the literature as being associated with firesetting in adults or adolescents were assessed using single items and short questionnaires which were all measured using a 7 point Likert Scale $(1=$ not at all like me, 7 = very strongly like me).

Anger was assessed using three items: I consider myself to be an angry person, I often get mad, I have a fiery temper, which were combined to produce a single score of how anger is experienced. The resulting scale had good internal reliability $(\alpha=.85)$. 
Emotional loneliness was measured using two items: I consider myself to be a lonely person, and I wish I had more friends. The two single items relating to loneliness were combined in the subsequent analyses and had an acceptable level of reliability $(\alpha=72)$.

Assertiveness was measured using a single item: I am an assertive person.

Boredom proneness was measured using a single item: I get bored easily.

Criminal associates was measured using a single item: I have friends who are criminals.

Attachment was measured using the Relationship Questionnaire (RQ; Bartholomew and Horowitz, 1991). The RQ assesses adult's attachment styles across different relationship domains. Participants read four short paragraphs referring to attachment styles (e.g., secure, preoccupied, fearful, and dismissing) and indicated which style is most applicable to them. In addition, Likert scale responses provide a continuous rating of individuals' attachment pattern $(1=$ disagree strongly, 7 = agree strongly $)$.

Parental bonding was measured using the Parental Bonding Instrument (PBI; Parker, Tupling and Brown, 1979). The PBI comprises 25 items measuring the perception of being parented up to age 16. Participants retrospectively comment on their perceptions of parental care (12 items relating to care, e.g., my mother/father was affectionate to me) and overprotection (13 items associated with overprotection, e.g., my mother/father tried to control everything I did) for their mother and father separately. Parental styles are rated using the headings (very like, moderately like, moderately unlike and very unlike) with higher scores indicating increased parental care or over protectiveness. The subscales of the PBI have been shown to have acceptable to good internal reliability (maternal care $\alpha=0.75$, maternal control $\alpha=0.82$, paternal care $\alpha=0.80$, and paternal control $\alpha=0.83$; Canetti et al., 1997). In the current study, alpha coefficients ranged from good to excellent (maternal 
care $\alpha=0.93$, maternal over protection $\alpha=0.90$, paternal care $\alpha=0.94$, paternal over protection $\alpha=0.87$, parental care $\alpha=0.95$, and parental over protection $\alpha=0.90$ ).

Impression management was assessed using the Balanced Inventory of Desirable Responding - Impression Management (BIDR-IM; Paulhus, 1984; 1988). The BIDR-IM comprises 20 items rated on a 5 -point Likert scale $(1=$ not true, $5=$ very true $)$. The BIDR-IM has established psychometric properties with acceptable to good internal consistency ( $\alpha$ ranging from .75 to .86 ; Paulhus, 1988). In the current study internal consistency was acceptable $\alpha=.75$.

\section{Procedure}

The research was approved by a University Research Ethics Committee (Reference: 20153388). The study was advertised to Prolific Academic members aged 18 to 23 years and living in the UK. An information sheet appeared before the start of the questionnaire and participants were informed that continuing with the study indicated consent. Participants were requested not to disclose any personally identifying information about themselves or fires they may have ignited and informed their responses were anonymous. The questionnaire took approximately 15 to 20 minutes to complete and participants had a maximum of 50 minutes to complete the study and were paid $£ 1.50$ for their time. Three attention check questions were included which prompted participants to select a particular response. Participants were informed they needed to successfully answer the attention checks to receive payment. On completion of the study a written debrief was provided.

\section{Results}

\section{Firesetting Prevalence and Features}

Twenty-five percent of participants $(n=60)$ reported igniting a deliberate fire. The majority of firesetting participants identified as male $(n=43,71.7 \%)$ and White British $(n=$ 45, 75.0\%). Firesetting and non-firesetting participants were similar in their level of 
qualifications with $90 \%(n=54)$ of firesetting participants having achieved five top grade GCSE qualifications $\left(\mathrm{A}^{*}\right.$ to $\left.\mathrm{C}\right)$ and $55 \%(n=33)$ having achieved three A Level qualifications graded $\mathrm{A} *$ to $\mathrm{C}$ (see Table I for an overview).

\section{INSERT TABLE I HERE}

On average, firesetting individuals reported igniting their most recent fire during midadolescence $(M=16$ years, $S D=3.09), 35 \%(n=21)$ continued to ignite fires in adulthood (18 to 22 years), and one ignited their first fire in adulthood (age 19). Just over half ignited multiple fires $(55 \%, n=33)$. Seventeen firesetting individuals $(28.3 \%)$ self-reported igniting five or more fires.

Targets of deliberate fires were predominantly paper products $(n=15,25 \%$; e.g., paper and books) followed by grass, shrubbery, or dry leaves $(n=14,23.3 \%)$, bins outside $(n=9,15.0 \%)$, and toilet roll dispensers $(n=8,13.3 \%)$. The majority of firesetting participants $(n=38,63.3 \%)$ reported igniting fires within one mile of their home (e.g., walking distance). Ten (16.7\%) reported copying a fire they had seen in the media. The majority of firesetting participants ignited their fires with other people $(n=39,65.0 \%)$ and reported being sober at the time of ignition $(n=51,85 \%)$ (see Table II).

\section{INSERT TABLE II HERE}

Although firesetting individuals reported engagement with criminal behaviour only three reported having criminal convictions; one for vandalism, one for antisocial behaviour, and one for antisocial behaviour and a violent crime. None reported having an arson conviction or having received any therapy for firesetting. The majority of firesetting 
participants $(n=49,81.7 \%)$ reported extinguishing their own fires, $16.7 \%(n=11)$ reported leaving the fire to burn itself out, none reported the fire service extinguishing their fires.

Firesetting participants reported multiple motivations for firesetting. The most frequently reported motives included curiosity and experimenting with fire $(n=48,80 \%)$, to create fun/excitement or alleviate boredom $(n=47,78.3 \%)$, and a love of fire $(30 \%, n=18)$.

Less common motivations included setting fire as part of a dare or prank $(8.3 \%, n=5)$, due to stress or frustration $(8.3 \%, n=5)$, to protect themselves $(5 \%, n=3)$, for another reason not specified $(5 \%, n=3)$, due to problems at home or school $(3.3 \%, n=2)$, vandalism $(3.3 \%, n=$ $2)$, to cover up another crime/destroy evidence $(1.7 \%, n=1)$. No participants reported being motivated by revenge, or for an insurance payout or financial gain.

In terms of preventative factors, $35 \%(n=21)$ of firesetting participants reported increased impulse control would have prevented them from firesetting. However, another third reported nothing would have prevented them from firesetting $(n=20)$. Less frequently reported preventative factors included increased fire safety knowledge $(13.3 \%, n=8)$, increased confidence to stand up to peers $(10 \%, n=6)$, increased parental supervision $(10 \%$, $n=6)$, being less bored $(3.3 \%, n=2)$, and other factors $(11.6 \%, n=7)$.

\section{Comparison of firesetting and non-firesetting participant characteristics}

\section{Demographic and historical variables}

Firesetting and non-firesetting participants could not be differentiated on the majority of demographic and historical factors (see Table I). Relative to non-firesetting individuals, those who set fires were more likely to report witnessing domestic violence $\chi^{2}(1, n=240)=$ $10.72, p \leq .001, \varphi=.23$, have easy access to fire paraphernalia as teenagers $\chi^{2}(1, n=240)=$ $10.47, p \leq .001, \varphi=.22$, and truanted more than once a week $\chi^{2}(1, n=240)=8.96, p \leq .001$, $\varphi=.21$. In addition, firesetting participants were significantly more likely to report 
experimenting with fire before age $10 \chi^{2}(1, n=240)=8.50, p \leq .001, \varphi=.20$, and have a family history of firesetting $\chi^{2}(1, n=204)=18.83, p \leq .001, \varphi=.32$.

Although firesetting and non-firesetting participants did not significantly differ on self-reported criminal convictions there were some differences in terms of engagement in illegal behaviour (See Table I). Firesetting individuals were significantly more like to report having engaged in robbery $\chi^{2}(1, n=240)=4.58, p \leq .03, \varphi=.16$, assault $\chi^{2}(2, n=240)=$ $11.53, p \leq .01, \varphi=.24$, shoplifting $\chi^{2}(1, n=240)=11.05, p \leq .001, \varphi=.27$, property vandalism $\chi^{2}(1, n=240)=8.28, p \leq .001, \varphi=.20$, having taken cannabis or dope $\chi^{2}(1, n=$ $240)=11.25, p \leq .001, \varphi=.23$, and taking 'harder' drugs such as Cocaine, Ecstasy or Heroin $\chi^{2}(1, n=240)=7.37, p \leq .001, \varphi=.19$.

\section{Personality measures}

After applying Bonferroni adjustments $(p \leq .007)$, independent samples t-tests showed firesetting participants scored significantly higher than non-firesetting participants on having criminal friends $t(81.53)=-3.45, p<.001$ (mean difference $=-.97,95 \% \mathrm{CI}:-1.52,-.41, d=$ .40) and on their levels of impulsivity, with firesetting participants reporting significantly higher levels of impulsivity compared to non-firesetting participants $t(238)=-3.77, p<.001$ (mean difference $=.85,95 \% \mathrm{CI}:-1.29,-.41, d=-.56$ ). There were no significant differences between the groups on the level of supervision as teenagers, experiences of anger, boredom,

\section{assertiveness, or emotional loneliness.}

The BIDR-IM was significantly negatively correlated with the FSS and the FPS when computed separately for both firsetting ( $r=-.47, r=-.34$ respectively) and non-firesetting participants ( $r=-.34, r=-.24$ respectively). Therefore, this was included as a covariate in subsequent analyses. 
Mean scale scores were calculated for firesetting and non-firesetting participants, see

Table III. Separate one-way between-groups multivariate analysis of covariance

(MANCOVA) examined any differences between firesetting and non-firesetting participants on the FSS and FPS. None of the assumptions of normality, linearity, outliers, multicollinearity, and homogeneity of variance-covariance were violated. Firesetting individuals scored significantly higher than non-firesetting individuals on both the total FSS score $F(2,236)=11.13, p<.001 ;$ Wilks' $\Lambda=.91 ; \eta_{\mathrm{p}}^{2}=.09 ; d=.78$, and the individual subscales $\left(\right.$ Antisocial: $F(1,237)=13.40, p<.001 ; \eta_{\mathrm{p}}{ }^{2}=.05 ; d=.64 ;$ Fire Interest: $F(1,237)=$ 13.16, $p<.001 ; \eta_{\mathrm{p}}{ }^{2}=.05 ; d=.62$ ). Firesetting individuals also scored significantly higher than non-firesetting individuals on the total FPS score, $F(4,234)=4.74, p<.01$; Wilks' $\Lambda=$ $.93 ; \eta_{\mathrm{p}}{ }^{2}=.08 ; d=.65$ and all subscales $\left(\right.$ Fascination $F(1,237)=9.65, p=.002 ; \eta_{\mathrm{p}}{ }^{2}=.04 ; d=$ .55, Behavioural Propensity $F(1,237)=18.21, p<.001 ; \eta_{\mathrm{p}}{ }^{2}=.07 ; d=.71$, Arousal Index $F(1,237)=9.83, p=.002 ; \eta_{\mathrm{p}}{ }^{2}=.04 ; d=.57$, and Antisocial Index $F(1,237)=4.94, p=.008$; $\left.\eta_{\mathrm{p}}{ }^{2}=.02 ; d=.33\right)$. Firesetting and non-firesetting participants did not significantly differ on the PBI or RQ.

\section{INSERT TABLE III HERE}

\section{Classifying firesetting and non-firesetting participants}

Firesetting and non-firesetting participants were distinguishable across 15 variables. To reduce the number of variables, some were collapsed into single overarching items (e.g., the drugs variables of Dope and Cannabis, and Cocaine, Ecstasy, or Heroin were combined as taken any illegal drugs; robbery, assault, shop theft, and vandalism were combined as criminal behaviour). The remaining nine variables could broadly be grouped as supervision and behavioural issues (e.g., witnessing domestic violence, experimenting with fire before age 10, and family history of deliberate firesetting), antisocial behaviours (e.g., having criminal friends, impulsivity, teenage access to fire paraphernalia, skipped class more 
than once a week, taken any illegal drugs, and participation in criminal behaviour), and fire related interests, attitudes, and propensities (e.g., Fire Setting Scale and Fire Proclivity

Scale). Three hierarchical binary logistic regression models examined the association between each group of factors and firesetting status. The BIDR-IM was entered into block one and the above-mentioned predictor variables were entered into block two.

The model for parental supervision and behavioural issues was significant $\chi^{2}(4, n=$ $204)=32.06, p<.001$ and therefore able to distinguish between firesetting and nonfiresetting participants. Overall, the model explained between 14.5\% (Cox and Snell R Square), and $22.2 \%$ (Nagelkerke R squared) of the variance in firesetting status, and correctly classified $79.4 \%$ of cases overall, $26.1 \%$ of the firesetting participants, and $94.9 \%$ of the nonfiresetting participants. Having experimented with fire before age $10(\mathrm{OR}=2.70)$ and having a family history of deliberate firesetting $(\mathrm{OR}=5.32)$ were significantly associated with firesetting status, having witnessed domestic violence was approaching significance $(p=.05$, OR $=2.60)$ (see Table IV).

The model for antisocial behaviours was also significant $\chi^{2}(7, n=240)=45.92, p<$ .001 , and therefore able to distinguish between firesetting and non-firesetting participants. The overall model explained between 17.4\% (Cox and Snell R Square), and 25.8\% (Nagelkerke R squared) of the variance in firesetting status, and correctly classified $79.2 \%$ of cases overall, $31.7 \%$ of firesetting participants, and $95.0 \%$ of the non-firesetting participants. Impulsivity $(\mathrm{OR}=1.37)$, teenage access to fire paraphernalia $(\mathrm{OR}=5.54)$, and criminal behaviour $(\mathrm{OR}=2.37)$ were statistically significant predictors of firesetting although odds rations were small (see Table IV).

The model for fire-related interests, attitudes, and propensities was also significant $\chi^{2}$ $(3, n=240)=28.31, p<.001$, and therefore able to distinguish between firesetting participants and non-firesetting participants. The model explained between $11.1 \%$ (Cox and 
Snell R Square) and 16.5\% (Nagelkerke R squared) of the variance in firesetting status, and correctly classified $75.8 \%$ of cases overall, $15 \%$ of firesetting participants and $96.1 \%$ of the non-firesetting participants. However, only the Firesetting Scale $(\mathrm{OR}=1.03)$ was a statistically significant predictor of firesetting status (see Table IV).

\section{INSERT TABLE IV HERE}

\section{Discussion}

This study sought to extend understanding of the prevalence and psychological characteristics associated with un-apprehended firesetting in a sample of 18 to 23 year old UK adults; representing the first empirical investigation of firesetting in an emerging adult population. Twenty-five percent of participants self-reported having set at least one deliberate fire since the age of 10 with just over half reporting having set multiple fires. Just under two thirds reported only setting fires in adolescence, however, just over a third reported continued firesetting in adulthood. The prevalence of un-apprehended firesetting identified in the current study is notably higher than that reported in both the NESARC survey $(1-1.3 \%$; Blanco et al., 2010; Vaughn et al., 2010) and in Barrowcliffe and Gannon's previous studies with UK community adults (11\% to $17.8 \%$; Barrowcliffe and Gannon, 2015, 2016; Gannon and Barrowcliffe, 2012). However, it is more aligned with those reported in community samples of adolescents (e.g., 27 to 29\%; Del Bove et al., 2008; MacKay et al., 2009). It is therefore possible that by restricting recruitment to those age 18 to 23 years, potential recall biases that may have occurred in previous studies were addressed and therefore this study provides a more accurate representation of the prevalence of un-apprehended firesetting in emerging adults. 
In terms of offence characteristics, the targets of firesetting tended to be small items such as paper, grass and bins and fires were set in the presence of others. If fires were extinguished, this was by the individual rather than the fire service. These findings are consistent with previous un-apprehended firesetting research (e.g., Barrowcliffe and Gannon 2015, 2016); however, in contrast, apprehended firesetting adults are reported to set fires alone and to property/buildings of personal or public significance (e.g., Canter and Fritzon, 1998; Ritchie and Huff, 1999; Rix, 1994). These subtle differences in fire behaviours may explain why some individuals go un-apprehended for firesetting, as their fires are smaller, less emotionally salient, and likely to be extinguished by the individual.

In terms of psychological characteristics, firesetting participants significantly differed from non-firesetting participants on levels of impulsivity, teenage access to fire paraphernalia, participation in un-convicted criminal behaviour, elevated fire interest and antisocial behaviours and an increased propensity to set fires, experimentation with fire before 10 years of age, and having a family history of firesetting. Having a family history of firesetting and teenage access to fire paraphernalia were variables most strongly associated with firesetting status. These findings are broadly consistent with research of both apprehended firesetting adults and adolescents (e.g., Del Bove et al., 2008; Gannon et al., 2013; MacKay et al., 2009; Martin et al., 2004; Rice and Harris, 1996) and research showing influences on fire learning (Thomas, MacKay, and Salsbury, 2012). However, there are some notable differences; for example, whilst un-apprehended individuals appear to have increased levels of antisocial behaviour compared to non-firesetting individuals, unlike apprehended samples, this behaviour appears to have gone undetected as indicated by the low number of participants with previous convictions. Further, despite being more likely than non-firesetting individuals to use substances, un-apprehended firesetting participants predominantly report 
not being intoxicated at the time of the firesetting which is in contrast to findings with apprehended samples (e.g., Ritchie and Huff, 1999; Rix, 1994).

In terms of motivations, the most frequently reported motives for firesetting by unapprehended individuals were to create excitement, alleviate boredom, or to satisfy curiosity; none of the participants who self-reported firesetting in this current study (nor previous UK un-apprehended firesetting studies) cited revenge as a motive. In contrast, research with apprehended firesetting individuals suggests revenge is one of the most common motivations firesetting whereas boredom is less common (Rix, 1994). It therefore appears unapprehended individuals are less likely to ignite fires for emotionally driven reasons but instead ignite fires for immediate gratification. This may also explain why perpetrators of unapprehended fires are likely to have smaller targets and therefore are less likely to come to the attention of the authorities.

Taken together, the findings from the current study highlight the importance of primary prevention initiatives for reducing the incidence of un-apprehended deliberate firesetting. More specifically, they emphasise the importance of initiatives for both parents and young people to reduce risk factors of parental supervision, access to fire paraphernalia, curiosity and interest in fire, and modelling of problematic fire use. Fire safety education represents an existing strategy that may hold value for preventing un-apprehended firesetting. However, further research is needed to understand the full range of risk and protective factors for un-apprehended firesetting. Understanding both factors that are associated with firesetting and those that protect individuals from engaging in this behaviour will provide useful targets for prevention and early intervention initiatives.

A notable strength of the current study is that it utilised an anonymous online survey to capture self-reported firesetting, overcoming limitations associated with previous research using face-to-face methods (e.g., Blanco et al., 2010; Vaughn et al., 2010). It also sought to 
overcome limitations with recall bias associated with previous research, by restricting participation to those age 18 to 23 years. That said, limitations of the research include its reliance on self-report measures to capture firesetting behaviour, the use of a crowdsourcing platform to recruit participants, and the reliance on single item questions to assess certain psychological characteristics (e.g., boredom, assertiveness, and antisocial associates). First, the firesetting disclosure question exclusively focused on self-reported fires that were for antisocial or fire interest purposes, potentially excluding individuals who set fires for other reasons (e.g., to communicate feelings of distress). Second, whilst crowdsourcing platforms are considered to provide more geographically and demographically diverse samples than university samples, they have also been criticised for not necessarily producing samples that are representative of the general population (i.e., high rates of Caucasian, highly educated, and student respondents; Peer, Brandimart, Samat, and Acquisti, 2017). However, research suggests crowdsourcing platforms are useful for obtaining high quality data, particularly for clinically relevant psychopathology, whilst also providing anonymity (Shapiro, Chandler, and Mueller, 2013). Finally, the use of single items to assess some psychological characteristics may have meant that differences between the two groups that may have been detected by more sensitive measures were missed. Future research would benefit from addressing the limitations associated with the current study to further our understanding of un-apprehended firesetting.

Whilst the current study extends previous research on un-apprehended firesetting, variables selected for inclusion in the study were based on the apprehended firesetting literature. Although there are some clear similarities between apprehended and unapprehended firesetting individuals, there are also some notable differences. Given unapprehended firesetting individuals appear to be emerging adults who are engaged in a range of antisocial behaviours, future research may benefit from examining whether psychological 
characteristics that are more broadly associated with antisocial behaviour in adolescents and emerging adults are also associated with firesetting. The more we can learn about unapprehended firesetting the better we can detect, intervene, and ultimately prevent this behaviour and the serious consequences it has. 
Arson Control Forum. (2003), Research Bulletin no.1 Arson: From Reporting to Conviction. Office of the Deputy Prime Minister, Crown copyright: West Yorkshire.

Barrowcliffe, E. R. and Gannon, T. A. (2015), "The Characteristics of un-apprehended firesetters living in the UK Community", Psychology, Crime and Law, Vol. 21 No. 9, pp.836853. doi:10.1080/1068316X.2015.1054385.

Barrowcliffe, E. R. and Gannon, T. A. (2016), “Comparing the Psychological Characteristics of Unapprehended Firesetters and Non-Firesetters Living in the UK”, Psychology, Crime and Law, Vol. 22 No.4, pp. 382-404. doi: 10.1080/1068316X.2015.1111365

Bartholomew, K. and Horowitz, L. M. (1991), “Attachment styles among young adults: A test of a four category model”, Journal of Personality and Social Psychology, Vol 61 No. 2, pp. 226244. doi:10.1037/0022-3514.61.2.226

Blanco, C., Alegria, A. A., Petry, N. M., Grant, J., Simpson, H. B., Liu, S., ... and Hasin, D. (2010), "Prevalence and correlates of firesetting in the US: Results from the national epidemiologic survey on alcohol and related conditions (NESARC)", Journal of Clinical Psychiatry, Vol. 71 No. 9, pp. 1218-1225. doi:10.4088/JCP.08m04812gry

Canetti, L., Bachar, E., Galili-Weisstub, E., De-Nour, A. K., and Shalev, A. Y. (1997), "Parental bonding and mental health in adolescence", Adolescence, Vol. 32 No. 126, p. 381.

Canter, D., and Fritzon, K. (1998), “Differentiating arsonists: A model of firesetting actions and characteristics", Legal and Criminological Psychology, Vol. 3 No. 1, pp.73-96.

Del Bove, G., Caprara, G. V., Pastorelli, C. and Paciello M. (2008), “Juvenile firesetting in Italy: relationship to aggression, psychopathology, personality, self-efficacy, and school functioning", European Journal of Child and Adolescent Psychiatry, Vol. 17, pp. 235-244. doi:10.1007/s00787-007-0664-6 
Del Bove, G. and Mackay, S. (2011). “An empirically derived classification system for juvenile firesetters", Criminal Justice and Behavior, Vol. 38 No. 8, pp.796-817.

Dickens, G. L. and Sugarman, P. (2012), “Adult firesetters: Prevalence, characteristics and psychopathology", Dickens, G. L. Sugarman, P. and Gannon T. A (Ed.s), Firesetting and Mental Health: Theory, Research and Practice, RCPsych, London pp. 3-27.

Dickens, G., Sugarman, P., Ahmad, E, Edgar, S., Hofberg, K., \& Tewari, S. (2007). Gender differences among adult arsonists at psychiatric assessment. Medical Sciences and the Law, 47(3), 233-238. doi:10.1258/rsmmsl.47.3.233

Gannon, T. A. and Barrowcliffe, E. R. (2012), "Firesetting in the general population: The development and validation of the Fire Setting and Fire Proclivity Scales”, Legal and Criminological Psychology, Vol. 17 No.1, pp. 105-122. doi:10.1348/135532510X523203

Gannon, T. A., Ó Ciardha, C., Barnoux, M. F. L., Tyler, N., Mozova, K., \& Alleyne, E. K. A. (2013). Male imprisoned firesetters have different characteristics than other imprisoned offenders and require specialist treatment. Psychiatry: Interpersonal and Biological Processes, 76, 349364. doi:10.1521/psyc.2013.76.4.349

Gannon, T. A., Ó Ciardha, C., Doley, R. M., \& Alleyne, E. (2012). The Multi-Trajectory Theory of Adult Firesetting. Aggression and Violent Behavior, 17, 107-121. doi:10.1016/j.avb.2011.08.001

George, D. and Mallery, P. (2003), SPSS for Windows step by step: A simple guide and reference, 11.0 update (4th ed.). Allyn and Bacon, Boston.

Goodman, J.K. and Paolacci, G. (2017), "Crowdsourcing consumer research", Journal of Consumer Research, Vol. 44 No. 1, pp.196-210. https://doi.org/10.1093/jcr/ucx047

Kolko, D. J. (1985). Juvenile firesetting: A review and methodological critique. Clinical Psychology Review, 5(4), 345-376. doi:10.1016/0272-7358(85)90012-1 
Kolko, D. J., \& Kazdin, A. E. (1986). A conceptualization of firesetting in children and adolescents. Journal of Abnormal Child Psychiatry 14, 49-61. doi:10.1007/bf00917221

Lader, D. (2021), Fire statistics data tables, Home Office, available at https://www.gov.uk/government/statistical-data-sets/fire-statistics-data-tables\#deliberatefires-attended, (accessed March 2021).

MacKay, S., Henderson, J., Del Bove, G., Marton, P., Warling, D., \& Root, C. (2006). Fire interest and antisociality as risk factors in the severity and persistence of juvenile firesetting. Journal of the American Academy of Child and Adolescent Psychiatry, 45(9), 1077-1084. doi:10.1097/01.chi.0000227881.50404.ca

MacKay, S., Paglia-Boak, A., Henderson, J., Marton, P. and Adlaf, E. (2009), "Epidemiology of firesetting in adolescents: Mental health and substance use correlates", Journal of Child Psychology and Psychiatry, Vol. 50 No. 10, pp. 1282-1290. doi:10.1111/j.14697610.2009.02103.x

Martin, G., Bergen, H. A., Richardson, A. S., Roeger, L. and Allison. S. (2004), “Correlates of firesetting in a community sample of young adolescents", Australian and New Zealand Journal of Psychiatry, Vol. 38 No. 3, pp. 148-1554. doi:10.1111/j.1440-1614.2004.01318

McCarty, C. A., \& McMahon, R. J. (2005). Domains of risk in the developmental continuity of firesetting. Behaviour Therapy, 36(2), 185-195. doi:10.1016/S0005-7894(05)80067-X

Parker, G., Tupling, H. and Brown, L. B. (1979), “A parental bonding instrument”, British Journal of Medical Psychology, Vol. 52, pp. 1-10.

Paulhus, D. L. (1988), Assessing self deception and impression management in self reports: The Balanced Inventory of Desirable Responding. Unpublished manual, University of British Columbia, Vancouver, Canada. 
Paulhus, D. L. (1984), “Two-component models of socially desirable responding”, Journal of Personality and Social Psychology, Vol. 46, pp. 598-609. doi:10.1037/0022-3514.46.3.598

Peer, E., Brandimarte, L., Samat, S. and Acquisti, A. (2017), "Beyond the Turk: Alternative platforms for crowdsourcing behavioral research", Journal of Experimental Social Psychology, Vol. 70, pp.153-163.

Rice, M. E. and Harris, G. T. (1996), "Predicting the recidivism of mentally disordered firesetters", Journal of Interpersonal violence, Vol. 11 No. 3, pp.364-375.

Ritchie, E. C., and Huff, T. G. (1999), "Psychiatric aspects of arsonists”, Journal of Forensic Science, Vol. 44 No. 4, 733-740. doi:10.1520/jfs14546j

Rix, K. J. (1994), “A psychiatric study of adult arsonists”, Medicine, Science and the Law, Vol. 34 No. 1, pp.21-34.

Root, C., MacKay S., Henderson , J., Del Bove, G. and Warling, D. (2008), “The link between maltreatment and juvenile firesetting: Correlates and underlying mechanisms", Child Abuse and Neglect, Vol. 32, pp. 161-176. doi:10.1016/j.chiabu.2007.07.004

Shapiro, D. N., Chandler, J. and Mueller, P. A. (2013), "Using Mechanical Turk to study clinical populations”, Clinical Psychological Science, Vol. 1, No. 2, pp.213-220.

Thomas, M., MacKay, S. and Salsbury, D. (2012), "Exposure to fire setting behavior on YouTube”, Journal of Adolescent Health, Vol. 51 No. 1, pp.99-100.

Vaughn, M. G., Fu, Q., Delisi, M., Wright, J. P., Beaver, K. M., Perron, B. E. and Howard, M. O. (2010), "Prevalence and correlates of fire-setting in the United States: Results from the National Epidemiological Survey on alcohol and related conditions", Comprehensive Psychiatry, Vol. 51, pp. 217-223. doi:10.1016/j.comppsych.2009.06.002

Watt, B. D., Geritz, K., Hasan, T., Harden, S., \& Doley, R. (2015). Prevalence and correlates of firesetting behaviours among offending and non-offending youth. Legal and Criminological Psychology, 20, 19-36. doi:10.1111/lcrp.12062 
Table I. Firesetting and non-firesetting participants background and demographic characteristics.

\begin{tabular}{|c|c|c|}
\hline 3 & $\begin{array}{l}\text { Firesetting } \\
(n=60)\end{array}$ & $\begin{array}{l}\text { Non-firesetting } \\
(n=180)\end{array}$ \\
\hline Variable & $M \quad(S D)$ & $M \quad(S D)$ \\
\hline \multicolumn{3}{|l|}{ Demographics } \\
\hline Age & $20.1(1.5)$ & $19.9(1.4)$ \\
\hline \multirow{2}{*}{ Siblings (number) } & $2.5(1.1)$ & $2.3(.9)$ \\
\hline & Percentage yes $(n)$ & Percentage yes $(n)$ \\
\hline Males & $71.7(43)$ & $42.2(76)$ \\
\hline Females & $28.3(17)$ & $57.8(104)$ \\
\hline White British & $75.0(45)$ & $74.4(134)$ \\
\hline White Other & $5.0(3)$ & $8.4(15)$ \\
\hline Black African & $1.7(1)$ & $1.7(3)$ \\
\hline Mixed ethnic background & $8.3(5)$ & $3.9(7)$ \\
\hline Indian & $1.7(1)$ & $5.0(9)$ \\
\hline Pakistani & $3.3(2)$ & 0 \\
\hline Chinese & $1.7(1)$ & $3.9(7)$ \\
\hline Other ethnic background & $3.3(2)$ & $2.8(5)$ \\
\hline Formal qualifications 5 GCSE $A^{*}$ to $\mathrm{C}$ & $90.0(54)$ & $89.4(161)$ \\
\hline Formal qualifications $3 \mathrm{~A}$ Levels $\mathrm{A} *$ to $\mathrm{C}$ & $55.0(33)$ & $65.0(117)$ \\
\hline History of enuresis & $11.7(7)$ & $8.3(15)$ \\
\hline Psychiatric illness diagnosis & $18.3(11)$ & $20.0(36)$ \\
\hline Physical disability diagnosis & $0(0)$ & $1.61(2)$ \\
\hline Behavioural problem diagnosis & $3.3(2)$ & $2.8(5)$ \\
\hline As a teenager had easy access to fire paraphernalia & $95.0(57)^{* *}$ & $74.4(134)$ \\
\hline Suspension from school & $10.0(6)$ & $6.7(12)$ \\
\hline Expulsion from school & $3.3(2)$ & $2.8(5)$ \\
\hline Deliberately skipped class more than once a week & $28.3(17)^{* *}$ & $11.1(20)$ \\
\hline History of suicide & $13.3(8)$ & $7.2(13)$ \\
\hline History of self-harm & $35.0(21)$ & $31.1(56)$ \\
\hline Exerted power over a partner & $10.0(6)$ & $2.8(5)$ \\
\hline Underage drinking & $70.0(42)$ & $57.8(104)$ \\
\hline Smoking & $63.3(38)$ & $51.7(93)$ \\
\hline Experimented with fire before the age of 10 & $50.0(30)^{* *}$ & $28.3(51)$ \\
\hline \multicolumn{3}{|l|}{ Self-reported criminal behaviour } \\
\hline Taken drugs e.g., Dope/Cannabis & $70.0(42)^{* * *}$ & $43.9(79)$ \\
\hline Taken drugs e.g., Cocaine, Ecstasy or Heroin & $35.0(21)^{* *}$ & $17.2(31)$ \\
\hline
\end{tabular}


Taken any drugs

$68.3(41)^{* * *}$

43.9 (79)

Assault

$18.3(11)^{* * *}$

$3.9(7)$

Sexual assault

0

0

Robbery

$11.7(7)^{*}$

3.3 (6)

Shop theft

$38.3(23) * * *$

16.7 (30)

Vandalism

$21.7(13)^{* *}$

$7.2(13)$

Burglary

1.7 (1)

0

Fraud

6.7 (4)

2.2 (4)

Car theft

0

0

Threatened someone with a weapon

0

0

Reported receiving a criminal conviction

$5.0(3)$

$0.1(1)$

\section{Family Background}

Lack of money (i.e., sometimes not enough money for food) 20.0 (12)

$16.7(30)$

Witnessed domestic violence

$28.3(17)^{* *}$

$10.0(18)$

Mother diagnosed with a psychiatric illness

$21.7(13)$

$20.0(36)$

Father diagnosed with a psychiatric illness

$20.0(12)$

9.4 (17)

Mother smoked

21.7 (13)

$22.2(40)$

Father smoked

28.3 (17)

$25.0(45)$

As a child had easy access to fire paraphernalia

46.7 (28)

$37.8(68)$

A family member also ignited a deliberate fire

$\chi^{2}$ with $95 \%$ confidence $* p<.05, * * p<.01, * * * p<.001$. 
Table II. Deliberate firesetting offence characteristics.

\section{Offence Characteristics}

\section{Number of deliberate fires ignited}

One

Two

Three

Four or more

\section{Ignition point and target}

One ignition point

Multiple ignition points

Paper, books or newspapers

Ignited countryside (e.g., grass/ shrubbery)

Ignited a bin outside

Ignited a toilet roll dispenser

Ignited clothing

Ignited a bin inside

Ignited an animal which was alive

Mattress or bedding

Ignited fire within a mile of home

Copied a fire seen in the media

Fires ignited alone or with accomplices

Ignited fire alone

Ignited fire with 1 other person

Ignited fire with 2 other people

Ignited fire with $3^{+}$people

\section{State of mind}

Believed they were in control of the fire

Sober at time of ignition

Planned the fire

Under the influence of drugs at time of ignition
$45.0(27)$

$16.7(10)$

$8.3(5)$

$30.0(18)$

$63.3(38)$

$36.7(22)$

$25.0(15)$

$23.3(14)$

15.0 (9)

$13.3(8)$

$10.0(6)$

8.3 (5)

3.3 (2)

1.7 (1)

$63.3(38)$

$16.7(10)$

$35.0(21)$

23.3 (14)

$16.7(10)$

$25.0(15)$

$3.3(2)$ 


\section{Motivations*}

Curiosity and experimentation with fire

$80.0(48)$

To create fun/excitement or alleviate boredom

$78.3(47)$

A love of fire

$30.0(18)$

Dare or prank

$8.3(5)$

Stress or frustration

Protection

Reason not specified

Problems at home or school

Vandalism

To cover up another crime/ destroy evidence

Revenge

Insurance payout or financial gain

\section{Extinguishing the fire}

Took part in extinguishing the fire

*Note: Some firesetters $(n=46,76.7 \%)$ indicated multiple motivations. 
Table III: Personality measures for firesetting and non-firesetting participants

\begin{tabular}{|c|c|c|c|c|}
\hline \multirow{2}{*}{ Items/Scale } & \multicolumn{2}{|c|}{ Firesetting } & \multicolumn{2}{|c|}{ Non-Firesetting } \\
\hline & $M$ & $S D$ & $M$ & $S D$ \\
\hline Anger & 10.29 & 4.78 & 8.75 & 4.25 \\
\hline Emotional loneliness & 8.25 & 3.02 & 8.26 & 3.34 \\
\hline Assertiveness & 4.22 & 1.61 & 3.79 & 1.60 \\
\hline Impulsivity & $4.57 * * *$ & 1.42 & 3.72 & 1.54 \\
\hline Boredom proneness & 5.02 & 1.41 & 4.72 & 1.43 \\
\hline Supervision as a teenager & 3.50 & 1.48 & 4.02 & 1.23 \\
\hline Criminal associates & $3.13 * * *$ & 2.0 & 2.17 & 1.48 \\
\hline FSS & $71.60 * * *$ & $(19.44)$ & 57.03 & $(17.76)$ \\
\hline Behavioural items & $31.03 * * *$ & $(10.34)$ & 24.89 & $(8.78)$ \\
\hline Fire Interest items & $40.57 * * *$ & $(13.52)$ & 32.14 & $(13.46)$ \\
\hline FPS & $57.67 * * *$ & $(13.34)$ & 49.09 & (12.97) \\
\hline Fire Fascination & $17.68 * * *$ & $(4.82)$ & 15.08 & $(4.62)$ \\
\hline Behavioural Propensity & $13.17 * * *$ & (3.64) & 10.73 & $(3.24)$ \\
\hline Fire Arousal & $16.48 * * *$ & $(4.25)$ & 13.97 & $(4.48)$ \\
\hline Antisociality & $10.33 *$ & $(3.38)$ & 9.31 & $(2.79)$ \\
\hline \multicolumn{5}{|l|}{ PBI } \\
\hline Maternal Care & 26.37 & $(7.62)$ & 27.79 & $(7.65)$ \\
\hline Maternal Over protectiveness & 14.57 & $(7.93)$ & 13.19 & $(7.39)$ \\
\hline Paternal Care & 21.96 & $(10.12)$ & 23.66 & $(8.47)$ \\
\hline Paternal Over protectiveness & 9.75 & $(7.19)$ & 10.61 & $(7.16)$ \\
\hline Parental Care & 48.20 & $(15.09)$ & 51.41 & $(14.40)$ \\
\hline Parental Over protectiveness & 24.53 & $(11.60)$ & 23.80 & $(12.16)$ \\
\hline BIDR - IM & 53.88 & $(11.58)$ & 58.06 & $(10.25)$ \\
\hline \multicolumn{5}{|c|}{ Attachment style based on Likert responding } \\
\hline Secure & 4.22 & $(1.91)$ & 4.05 & $(1.75)$ \\
\hline Fearful & 4.22 & $(1.90)$ & 4.52 & $(1.81)$ \\
\hline Preoccupied & 3.65 & $(1.89)$ & 4.03 & $(1.77)$ \\
\hline
\end{tabular}



Dismissing
4.00
(1.94)
3.77
$(1.85)$

Attachment style based on categorical responding

\begin{tabular}{lllll} 
& \multicolumn{2}{l}{ Percentage } & $($ n) & Percentage \\
\cline { 2 - 5 } Secure & 36.7 & $(22)$ & 31.1 & $(56)$ \\
Fearful & 18.3 & $(11)$ & 21.1 & $(38)$ \\
Preoccupied & 25.0 & $(15)$ & 35.0 & $(63)$ \\
Dismissing & 20.0 & $(12)$ & 12.8 & $(23)$
\end{tabular}

${ }^{*} p \leq .05,{ }^{* *} p<.01,{ }^{* * *} p \leq .001$ 
Table IV. Logistic Regressions predicting firesetting status based on parental supervision and behavioural issues, anti-social behaviours and fire related interests, attitudes and propensities

Odds

$\beta \quad$ S.E. Wald df $p \quad$ Ratio $95 \%$ C.I. For Odds Ratio

\section{Parental supervision and behavioural issues}

Lower Upper

BIDR-IM

$-0.2 \quad .02$

$\begin{array}{lll}1.30 & 1 & .26\end{array}$

.98

.95

1.01

Witnessing domestic violence

.96

.49

2.60

2.09

13.52

Experimented with fire before age 10

$\begin{array}{lllll}1.00 & .38 & 7.02 & 1 & .01\end{array}$

2.72

1.00

6.77

Family history of deliberate

firesetting

$\begin{array}{lllll}1.67 & .48 & 12.35 & 1 & <.001\end{array}$

5.32

1.30

5.70

Constant

$\begin{array}{lllll}-.98 & 1.02 & .93 & 1 & .33\end{array}$

.38

\section{Anti-social behaviours}

BIDR-IM

Criminal friends

Impulsivity

Teenage access to fire paraphernalia

Skipped class more than once per week

Taken any drugs

Participated in criminal

behaviour

Constant

Fire related interests, attitudes, and propensities

BIDR-IM

Fire Setting Scale

Fire Proclivity Scale

Constant

$\begin{array}{llllllll}.01 & .02 & .38 & 1 & .54 & 1.01 & .98 & 1.05 \\ .13 & .10 & 1.73 & 1 & .19 & 1.14 & .94 & 1.40 \\ .31 & .12 & 6.46 & 1 & .01 & 1.37 & 1 . .07 & 1.74 \\ 1.71 & .64 & 7.22 & 1 & .01 & 5.55 & 1.59 & 19.36 \\ .61 & .44 & 1.88 & 1 & .17 & 1.84 & .77 & 4.39 \\ .31 & .36 & .70 & 1 & .40 & 1.36 & .67 & 2.77 \\ .86 & .38 & 5.10 & 1 & .02 & 2.37 & 1.12 & 5.03 \\ -5.44 & 1.47 & 13.77 & 1 & <.001 & .004 & & \end{array}$

$\begin{array}{lllll}-.01 & .02 & .24 & 1 & .63\end{array}$

.99

.96

1.02

$\begin{array}{lllll}.03 & .01 & 7.34 & 1 & .01\end{array}$

1.03

1.01

1.06

$\begin{array}{lllll}.02 & .02 & 1.79 & 1 & .18\end{array}$

1.02

.99

1.05

$\begin{array}{llllll}-4.32 & .75 & 33.34 & 1 & <.001 & .01\end{array}$

